\title{
Factors Influencing Farmers' Adoption of Protected Agriculture: A Case of Vegetable Farmers in Dry Zone Sri Lanka
}

\author{
Nadeesha Dias*, Thilani Munaweera and Sidath Bandara \\ Hector Kobbekaduwa Agrarian Research and Training Institute, Sri Lanka
}

*Corresponding author: Nadeesha Dias, Research officer, Hector Kobbekaduwa Agrarian Research and Training Institute, Sri Lanka

\begin{abstract}
The farmers' adoption of Protected Agriculture (PA) in dry zone vegetable cultivation is considerably low in Sri Lanka. However, a few farmers have been practiced PA technologies to minimize negative impacts of climate change on vegetable production in dry part of Sri Lanka. Rain shelters were identified as the main type of PA technology used by dry zone vegetable farmers followed by poly tunnels. Understanding the factors that influencing farmers' adoption to PA could be more useful to popularize the technology in suitable areas while formulating policies to overcome some barriers for adoption. This study analyzed the factors influencing farmers' adoption of PA for vegetable cultivation in dry zone of Sri Lanka. A total of 120 vegetable farmers from 12 Agrarian service centers (ASC) in Anuradhapura and 2 ASC in Matale districts were selected randomly to identify the factors that would be influencing farmers' adoption on PA technologies for vegetable production in the dry zone of the country. Pre tested structured questionnaire were used for the survey in data collection. Binary logistic regression model was applied to identify the factors affecting on adoption to PA by vegetable farmers. Results reveal that farmers age, household size, cultivated extent, access to credit, access to new technologies, access to extension services and primary employment have a significant effect on adoption to PA. These results highlighted that importance of extension services and financial support to promote PA technologies for small scale vegetable farmers in dry zone.
\end{abstract}

Keywords: Protected agriculture, Vegetables, Adoption, Binary logistic regression

\section{Introduction}

Vegetables are major component of Sri Lankans' daily diet and there is a constant demand for vegetables in local market. Vegetable farming system in Sri Lanka mainly divided into two farming systems, there are up country and low country vegetable farming systems [1]. In both farming systems vegetables are predominantly cultivated in open fields using conventional farming methods. However, open field vegetable cultivations are highly depending on weather conditions mainly rainfall. In recent times vegetable production has been undergoing rigorous fluctuations due to unpredictable weather conditions in the country [2]. Compared to other climatic zones in the country, dry zone is more vulnerable to unexpected extreme climatic events such as droughts and floods [3]. As the major vegetable producing area, it is needed to identify and implement new farming technologies to minimize the impacts of extreme climatic events on vegetable production to maintain constant vegetable supply in the country. Adoption to protected agriculture on vegetable production will be one of the effective solution for minimize the impacts of these extreme climatic events.

Protected Agriculture (PA) is identified as one of the feasible adaptation strategy to minimize the impacts of climate changes on vegetable production as well as off seasons production with limited resources [4]. PA can be defined as cropping techniques where in the micro climate surrounding of the plant body is controlled partially or fully as per the requirement of the plant species grown during their period of growth [5]. PA technology involves the cultivation of vegetables especially in designed protective structures such as glass houses, poly tunnels, net houses and rain shelters where in the factors like temperature, humidity, light, soil, water and fertilizers 
are manipulated to attain maximum produce as well as allow a regular supply of them even during an off season [6]. Research results have shown that by adopting PA, productivity of vegetable crops can be increased by three to five times as compared to open field cultivations [7].

About 115 countries in the world are using PA technologies for vegetable production commercially. China is the major country using PA and 90 percent of its protected cultivations used for vegetable production [6]. Several studies showed that countries like India, Pakistan, Afghanistan, Israel and Iran are successfully practicing vegetable cultivation using PA under extreme climatic conditions. Capsicum, tomato, cucumber, brinjal, leafy vegetables and many other tropical vegetables are cultivated in these countries using PA and it was observed higher yield when compared to open field conditions $[4,6]$.

PA was introduced to Sri Lanka somewhere around 1987 and it has been adopted mostly by the middle class farmers [8]. Main purposes of introduction of PA farming are to minimize the impacts of erratic weather and provide optimum environmental for horticultural crop production as well as attraction of younger generation for agricultural sector with modern technologies $(2,9)$. PA is currently practiced mainly in up country and low country wet zone areas and very less in dry zone areas. Most commonly cultivated vegetables are pepper, tomato, cauliflower, lettuce, broccoli and Japanese cucumber. Frequently used PA structures in the country are net houses, poly tunnels and rain shelters [9]. Niranjan [8] mentioned that PA has a high potential for expansion into different agro ecological regions in the country with suitable protected structures for cultivation of vegetables. However, due to the requirement of high initial capital and technical knowledge limited number of farmers adapted to PA technologies with their own funds.

By adopting PA, farmers can look forward to a better and additional remuneration for high quality produce all year round with an efficient use of resources. Farmers adoption of different agricultural innovations and technologies is determined by different factors. Therefore, identification of most influencing factors on adoption to PA technologies is important in future research and policy formulations to promote PA for vegetable cultivations in the country as one of the possible adaptation method to minimize the impacts of climate changes in vegetable production in dry zone and increase the off season vegetable production in the country. This study was mainly focused to identify the factors influencing farmers' adoption of vegetable cultivation under protected agriculture technologies in dry zone.

\section{Theoretical Framework of Study}

Adoption may be defined as the integration of an innovation into farmers' normal farming activities over an extended period
[10]. Various theoretical perspectives explained the behavior of adoption on new technologies. Innovation diffusion theoretical perspective, the economic constraints theoretical perspective and the adopter perception theoretical perspective are three different theories commonly used to explain farmers' adoption behavior and factors affecting to technology adoption in previous studies $[10,11]$. Information dissemination is identified as a key factor influencing adoption decision in innovation diffusion theoretical perspectives. The adoption decision process is viewed as a series of linear stages starting by the knowledge stage followed by a persuasion, decision, implementation and finally confirmation stages [11]. The economic constraints theoretical perspective states that adoption is influenced by economic factors and economic constraints due to the asymmetric distribution of resources. Lack of ownership and access to capital constrain farmers from adopting new innovations [12]. The adopter perceptions theoretical perspective identifies farmers' perceptions as the key to the adoption of a particular farming technology [11]. This study integrated these three theories in to developing a conceptual understanding of the adoption of the PA technologies by farmers.

There is vast array of literatures on factors that determine agricultural technology adoption. Factors affecting to technology adoption is categorized in different ways in previous studies and there is no clear distinguishing feature between variables in each category. Categorization of factors is done according to the investigating technology, the study location and researchers' preference [13]. Kabir [14] categorized the determinants of technology adoption in to four broad categories of economic, social, institutional and management. Howely [15] categorized the factors affecting farmers' adoption to new technology in to a personal, social, cultural, institutional and economic factors as well as on the characteristics of the technology. In another studies factors influencing on agricultural technology adoption were categorized into technological, economic, institutional and household specific factors $[13,16]$. In previous studies, farmers age, educational level, gender, family size, farming experiences, farm size, primary employment, off farm income, social networks, membership in farmer organizations, access to credit, access to extension services and trainings, access to new technologies, labour availability, cost of new technology and net gain from technology are commonly identified as factors influencing on farmers' adoption to new technology $[13,14,16-20]$.

\section{Methodology}

Twelve Agrarian Service Centers (ASC) in Anuradhapura and two ASC in Matale which belongs to the dry zone were selected purposively for data collection with consideration of presence of farmers who are practicing vegetable cultivation using PA technologies. Among the different types of PA technologies, rain shelters are the predominant type of protected structures used by 
dry zone vegetable farmers. Other than that there are small number of poly tunnels also used by farmers for vegetable cultivations. Therefore, hereafter in this study PA term is used to denote rain shelters and polytunnels. Rain shelter is a simple form of protected structure made with Galvenized Iron (GI) pipes and only roof of the structure is covered with water resistant low density polyethylene film. It is mainly used to minimize the impact of heavy rainfall on cultivated crops and partially controlled the evapotranspiration by acting like a roof. Poly tunnels are relatively high tech protected structures and frame of structure constructed with GI pipes. The structure is fully covered with UV stabilized transparent polyethylene films. Microclimate within the structure is partially or fully controlled in this structures. The study sample was divided into two groups of farmers, those who adopted (adopters) vegetable cultivation under PA and those who have not been adopted the PA but practicing conventional vegetable cultivation within a same locality. Seventy farmers who have been practiced vegetable cultivation under PA and fifty conventional vegetable farmers were selected randomly for data collection. Total sample size was 120 including both PA and conventional vegetable farmers.

To achieve the objective of the study primary data was collected through household questionnaire survey using pre tested semi structured questionnaire. Two separate semi structured questionnaires were used to collect data from adopters and nonadopters of PA. Data on socio economic characters and present status of vegetable farming were collected through individual face to face interviews and data was analyzed using descriptive statistics and binary logistic regression method. Descriptive statistics used to describe the socio economic characters of sample farmers. The factors affecting to vegetable cultivation under PA technologies were analyzed using binary logistic regression method.

\section{Analytical Framework: Binary Logistic Regression Model}

Logistic regression model is one of the best analytical tool commonly used for analyze the farmer adoption decisions on new technologies $[11,21]$. Since the adoption of PA is a dichotomous or binary dependent variable, with the option of either adoption or rejection, the binary logistic regression model was applied [12]. It explores the degree and direction of relationship between independent and dependent variables in the adoption of PA at the household level. The dependent variable in this study was the farmer being an adopter or non-adopter of PA technology. Accordingly, adoption of PA technologies in dry zone assumed to be influenced by set of independent variables and is specified as follows.

Where the subscript $i$ means the $i^{\text {th }}$ observation in the sample. $\mathrm{P}$ is the probability of that a farmer adopts the PA and (1-P) is the probability that a farmer does not adopt PA. is the intercept term and,... and are the coefficients to be estimated related to independent variables $\mathrm{X}_{1}, \mathrm{X}_{2}, \ldots \ldots . ., \mathrm{X}_{\mathrm{k}}$. Based on literature, scope of the study and the availability of data following independent variables were selected for analysis *(Table 1$)$.

Table 1: Independent variables used in Binary logistic regression model .

\begin{tabular}{|c|c|c|}
\hline Variable & Type & Type of measurement \\
\hline Farmers' age & Continuous & No of years \\
\hline Education & Continuous & Number of years schooling \\
\hline Gender & Dummy & $1=$ male, $0=$ female \\
\hline Family size & Continuous & $\begin{array}{c}\text { Total no of family } \\
\text { members }\end{array}$ \\
\hline Primary employment & Dummy & $1=$ Agriculture, $0=$ other \\
\hline Access to credit & Dummy & $1=$ yes, $0=$ no \\
\hline $\begin{array}{c}\text { Access to extension } \\
\text { services }\end{array}$ & Continuous & $\begin{array}{c}\text { No of meetings with } \\
\text { Extension Officer per } \\
\text { season }\end{array}$ \\
\hline $\begin{array}{c}\text { Vegetable cultivating } \\
\text { area }\end{array}$ & Continuous & $\begin{array}{c}\text { ha } \\
1=\text { yes, } 0=\text { no }\end{array}$ \\
\hline $\begin{array}{c}\text { Membership in farmer } \\
\text { organization }\end{array}$ & Dummy & $1=$ yes, $0=$ no \\
\hline $\begin{array}{c}\text { Access to new } \\
\text { technologies }\end{array}$ & Dummy & $\begin{array}{c}1=\text { Participated for } \\
\text { training, } 0=\text { no }\end{array}$ \\
\hline Trainings & Dummy & $\begin{array}{c}1=\text { Received a subsidy, } \\
0=\text { no }\end{array}$ \\
\hline Subsidies & Dummy \\
\hline
\end{tabular}

\section{Results and Discussion}

\section{Summary of socio demographic characteristics of respondents}

Socio demographic characters of sample farmers show slight variations between adopters and non-adopters (Table 2). The results show that majority of PA adopted farmers (53\%) belongs to 31 to 45 years' age group while majority of non-adopters (42\%) belongs to 46 to 60 years' age group. It indicates that the younger generation has trusted more on PA technologies. Even though both groups received formal education but, the farmers who have adopted PA shows comparatively a higher education status while two graduates also within it. Engagement of female farmers for vegetable cultivation under PA (11\%) is higher than the conventional vegetable cultivation (2\%). Working under PA is quite easier than the working on open field and most of PA structures are constructed near to the farm houses might be the major factors for the female involvement to PA vegetable cultivation. There isn't considerable difference between the household size in both adopters and non-adopters. In both groups majority of farm families consisted with four to five members with the 59 percent in adopters and 60 percent in non-adopters respectively. As shows in Table 02 primary employment of the majority of the households 
is agriculture. From the conventional vegetable famers 78 percent are relied on vegetable cultivation as main income source and this value is only 31 percent in PA farmers. It has been highlighting the

Table 2: Socio demographic characteristics of respondents. diversified nature of PA farmers' income activities than conventional farmers.

\begin{tabular}{|c|c|c|c|c|c|}
\hline \multirow{2}{*}{ Character } & \multirow{2}{*}{ Description } & \multicolumn{2}{|c|}{ Adopters (70) } & \multicolumn{2}{|c|}{ Non adopters(50) } \\
\hline & & Frequency & Percentage (\%) & Frequency & Percentage (\%) \\
\hline \multirow{4}{*}{ Age } & $<30$ years & 6 & 9 & 2 & 4 \\
\hline & 31 to 45 years & 37 & 53 & 18 & 36 \\
\hline & 46 to 60 years & 23 & 33 & 21 & 42 \\
\hline & $>61$ years & 4 & 5 & 9 & 18 \\
\hline \multirow{4}{*}{ Education } & $<$ Grade 5 & 1 & 1 & 9 & 18 \\
\hline & Grade $6-11$ & 52 & 75 & 33 & 66 \\
\hline & Grade $11-13$ & 15 & 21 & 8 & 16 \\
\hline & Degree & 2 & 3 & - & - \\
\hline \multirow{2}{*}{ Gender } & Male & 62 & 89 & 49 & 98 \\
\hline & Female & 8 & 11 & 1 & 2 \\
\hline \multirow{3}{*}{ Household size } & $<=3$ members & 25 & 36 & 16 & 32 \\
\hline & 4 to 5 members & 41 & 59 & 30 & 60 \\
\hline & $>=6$ members & 4 & 5 & 4 & 8 \\
\hline \multirow{9}{*}{ Primary employment } & Vegetable cultivation & 22 & 31 & 39 & 78 \\
\hline & Paddy farming & 10 & 14 & 8 & 16 \\
\hline & Big onion cultivation & 13 & 19 & 0 & 0 \\
\hline & Other crop cultivation(Fruits/perennial) & 8 & 11 & 0 & 0 \\
\hline & Animal husbandry & 3 & 4 & 1 & 2 \\
\hline & Government jobs & 6 & 9 & 1 & 2 \\
\hline & Private sector jobs & 4 & 5 & 0 & 0 \\
\hline & Self employed & 2 & 3 & 1 & 2 \\
\hline & Non agricultural labour & 2 & 3 & 0 & 0 \\
\hline
\end{tabular}

\section{Factors affecting to adoption of PA technologies}

Results for the Tobit model was significant at the 0.05 percent level based on a model chi square statistics. Significant loglikelihood and LR Chi-square values imply that the model fitted well and the explanatory variables used in the model are collectively able to explain the determinants of adoption of PA technologies by dry zone vegetable farmers.
Table 03 shows the results of binary logistic regression model. The results of the model of farmers' propensity to adopt PA technologies indicate that seven of the twelve independent variables significantly influence the farmers' propensity to adopt PA technologies in the study area. These include age, household size, vegetable cultivation extent, access to credit, access to new technologies, and primary employment (Table 3).

Table 3: Results of binary logistic regression model.

\begin{tabular}{|c|c|c|c|}
\hline Variable & Coefficient & Standard error & Z value \\
\hline Constant & 3.928 & 3.292 & 1.19 \\
\hline Age* & -0.048 & 0.028 & -1.73 \\
\hline Gender & -1.698 & 1.452 & -1.17 \\
\hline Education & 0.151 & 0.154 & 0.98 \\
\hline Household Size* & -0.513 & 0.300 & -1.71 \\
\hline Primary employment* & -1.868 & 0.958 & -1.95 \\
\hline Cultivation extent*** & 1.695 & 0.495 & 3.42 \\
\hline Access to credit** & 1.747 & 0.880 & 1.98 \\
\hline Membership of the farmer society & 0.124 & 0.789 & 0.16 \\
\hline
\end{tabular}




\begin{tabular}{|c|c|c|c|}
\hline Access to extension service** & 0.059 & 0.024 & 2.51 \\
\hline Access to new technology** & 2.033 & 0.886 & 2.29 \\
\hline Training & 0.171 & 0.668 & 0.64 \\
\hline Subsidies & 0.422 & 0.660 & 0.64 \\
\hline \multicolumn{4}{|c|}{ LR chi2(12) $=76.0$} \\
\hline \multicolumn{4}{|c|}{ Prob $>$ chi $2=0.0000$} \\
\hline \multicolumn{4}{|c|}{ Pseudo R2 = 0.4699} \\
\hline
\end{tabular}

Age is a primary character in adoption decision and it is identified as one of the most important factor that influences the probability of adoption of new technologies. Age may have a negative, positive or not significantly influence on technology adoption [17, 19]. The binary logistic regression model results show that the age variable is an important factor influencing the adoption decision on PA technologies. Age of the farmer was negatively influenced PA technology adoption and it was significant at the 10 percent significance level. The negative relationship between age and adoption indicates the receptiveness toward technology among the younger farmers. Adoption of the technology by the younger farmers may be attributable to the fact that younger farmers are more likely to use new technologies rather than practicing conventional methods of farming. As cited by Mwangi \& Kariuki [13], in most studies age has been found to have a negative relationship with adoption of technology. This negative relationship is explained as younger farmers are typically less risk averse and more willing to try new technologies while older farmers are high risk averse and no interest in long term investment for new technologies. These results confirmed findings from the work of Alam [18], Arellanes [22] and Nyanga [12] that older farmers were accustomed to conventional methods of farming and were unlikely to change while younger farmers were faster to adopt new technology.

Most of the studies of technology adoption are identified land size as one of important determinant of technology adoption which can be affected positively, negatively or neutral relationship with adoption [13]. In this study also land extent cultivated with vegetables is significantly and positively influenced the adoption on PA technologies in sample area. This could be because farmers with larger cultivable lands are more market oriented commercial farmers hence they have good market linkages and access. Since they can provide continuous supply to the markets with larger quantities they may have develop good linkages with supermarkets that demand quality products. Farmers with larger land parcels are more likely to invest new technologies like PA that could minimize the climate risks and ensure the continuous supply even in off seasons. Further, discussion with farmers revealed that small-scale farmers generally lack with financial resources to invest in costly PA technologies. These findings are same with findings of Akudugu [17], Alam [18] and Farid [20] as farmers with large land size are more likely to adopt modern agricultural technologies.
Household size significantly relates with propensity to adopt PA practices at $10 \%$ level of significance. The result shows that farmers with small household will have high propensity to move for protected agricultural technologies. Arene [23] and Bello [24] reported a positive and significant relationship between adoption and household size. Labour has become one of the major constraint factors in Sri Lanka hence younger farmers with less number of family labour are more likely to transfer for less labour demanding technologies. However, in another study conducted by Alam [18] identified that household size did not affect toward the level of technology adoption.

The provision of support services, such as credit, has been shown to increase the adoption of improved technologies [25]. Farmers without cash and no access to credit find it very difficult to obtain and adopt new technologies. The results of this study indicate that the variable 'access to credit' has a positive and significant influence on the likelihood of adoption of PA, which is consistent with reports from previous studies [26, 27]. As discussed earlier, not like in conventional cultivation adoption of PA technology needs high initial investment which prevents farmers from adopting it. The variable that captures the subsidy effect on adopting is not significant in the analysis by emphasizing the need of increasing the availability of credit rather than promoting subsidies that have dead weight losses. This validates the condition that farmers with high accessibility to credit are more willing to use PA technologies.

The extension services have identified as very important aspect in explaining adoption decisions. Extension officers acts as a link between innovators and end users of technology. Previous studies show that extension services have positive relationship with new technology adoption [13]. The variables that measure the effectiveness of extension service, access to extension services measured by the number of meeting with Extension Officer in a cultivation season and it is positively significant at 5 percent significance level. Therefore, farmers who have more frequent visits from extension workers are more likely to adopt technologies or farming practices that they are exposed to through extension services. In this case, frequent extension services increased the farmer adopting PA agriculture as a farming practice. Similar relationship was observed by Akugudu [17], Bello [24], and Alam [18] as farmers have more access to extension services are highly adopted for modern agricultural production technologies. 
Access to new technology is identified as another factor that affects positively and significantly to adoption of PA technologies by dry zone farmers. Access to new technology is important for farmers to identify the benefits and effectiveness of new technologies. However, access to information of new technology can be negatively affect for technology adoption. Therefore, it is important to disseminate reliable and accurate information on technology for farmers [13].

The dummy variable that explains the type of primary employment of the farmer is significantly and negatively influencing on the decision of using protected agricultural technologies among the sample farmers. Farmers whose primary employment is agriculture are poor adopters than the farmers who are not completely rely on agriculture as income source. This could be dues to part time farmers are more willing to use less labour intensive technologies and they have financial stability to invest in capital intensive technologies. Farmers with high off farm income can overcome credit constraints for technology adoption. However, in some technologies there is a positive relationship of technology adoption with primary employment. Labour intensive technologies requires more labour for the afoption and have positive relationship with on farm income [13].

\section{Conclusion}

The binary logistic regression results show that factors associated with the adoption of PA technology were the age of the farmer, household size, access to credit, access to technology type of primary employment, access to extension services and the total vegetable cultivated land in hectare (ha). Working with the elder farmers with limited formal education can be a challenge when introducing new technologies such as protected agriculture. This finding highlights the need of targeting the suitable young people of the farming community to promote advanced technologies like PA. Findings of the logistic regression highlight the importance of increasing the access to credit which is one of the major constraints to adopt new technologies in agriculture among small scale vegetables farmers in dry zone of Sri Lanka. Also study has shown the importance of extension services in promoting new farming technologies. Access to extension services as well as intensity of the extension services are critical in determining the level of adoption.

\section{References}

1. Padmajani MT, Aheeyar MMM, Bandara MACS (2014) Assessment of Pesticide usage in Upcountry vegetable farming in Sri Lanka, HARTI research report No 164, Hector Kobbekaduwa Agrarian Research and Training Institute, Colombo, Sri Lanka.

2. Wijerathna M, Weerakkody W, AP, Kirindigoda S (2014) Factors Affecting the Discontinuation of Protected Agriculture Enterprises in Sri Lanka, The Journal of Agricultural sciences 19(2): pp 78-87.

3. Eriyagama N, Smakhtin V, Chandrapala L, Fernando K (2010) Impacts of climate change on water resources and agriculture in Sri Lanka: A review and preliminary vulnerability mapping, Colombo, Sri Lanka: International water Management Institute.
4. Abukari MK, Tok ME (2016) Protected cultivation as Adaptive response in climate change policy: The case of smallholders in Northern Ghana, Journal of Emerging trends in economics and management sciences 7(5): pp 307-321.

5. Mishra GP, Singh N, Kumar H, Singh SS (2010) Protected Cultivation for Food and Nutritional Security at Ladakh. Defence Science Journal 61(2): pp 219-225.

6. Sabir N, Singh B (2012) Protected cultivation of vegetables in global arena: A review. Indian Journal of Agricultural Sciences 83(2): pp123135.

7. Santosh DT, Tiwari KN, Singh VK (2017) Influence of different protected cultivation structures on water requirements of winter vegetables. International Journal of Agriculture, Environment and Biotechnology, vol 10(1): pp 93-103.

8. Niranjan F, Gunasena HPM, Sakalasooriya MB (2005) Controlled environment agriculture in Sri Lanka. Sri Lanka Council for Agricultural Research Policy.

9. Kumara SK, Weerakkody R, Epasinghe S (2015) Viability of controlled environmental agriculture for vegetable farmers in Sri Lanka, Research report 179, Hector Kobbekaduwa Agrarian Research and Training Institute.

10. Melesse B (2018) A review on factors affecting adoption of agricultural new technologies in Ethiopia. Journal of Agricultural Science and Food Research 9(3).

11. Ntshangase NL, Muroyiwa B, Sibanda M (2018) Farmers' perceptions and factors influencing the adoption of no-till conservation agriculture by small-scale farmers in Zashuke, KwaZulu-Natal Province. Sustainability 10(2): 555.

12. Nyanga PH (2012) Factors influencing adoption and area under conservation agriculture: A mixed methods approach. Sustainable Agriculture Research 1(2): pp 27-40

13. Mwangi M, Kariuki S (2015) Factors determining adoption of new agricultural technology by smallholder farmers in developing countries. Journal of Economics and sustainable development 6(5): pp 208-216.

14. Kabir MH, Rainis R (2013) Determinants and Methods of Integrated Pest Management adoption in Bangladesh: An environment friendly approach. American Eurasian Journal of Sustainable Agriculture 7(2): pp 99-107.

15. Howley P, Donoghue C, Heanue K (2012) Factors Affecting Farmers' Adoption of Agricultural Innovations: A Panel Data Analysis of the Use of Artificial Insemination among Dairy Farmers in Ireland. Journal of Agricultural Science 4.

16. Silva KNN, Broekel T (2016) factors constraining farmers' adoption of new agricultural programme in Hambantota District in Sri Lanka: Perceptions of Agriculture extension services, Proceedings of $13^{\text {th }}$ International conference on Business management pp: 378-398.

17. Akudugu MA, Guo E, Dadzie SK, (2012) Adoption of modern agriculture production technologies by farm households in Ghana: What factors influence their decisions. Journal of Biology Agriculture and Healthcare 2(3).

18. Alarm MN (2015) Effect of farmers socio economic toward adoption level of Agricultural technology in Sigi regency Indonesia. Journal of Applied Sciences 15(5): pp 826-830.

19. Amare A, Simane B (2017) Determinants of smallholder farmers' decision to adopt adaptation options to climate change and variability in the Muger Sub basin of the upper Blue Nile basin of Ethiopia, Agriculture and food security 6 .

20. Farid KS, Tanny NZ, Sarma PK (2015) Factors affecting adoption of improved farm practices by the farmers of Northern Bangladesh, J Bangladesh Agril Uni 13(2): pp 291-298. 
21. Karidjo BY, Wang Z, Boubacar Y, Wei C (2018) Factors influencing farmers' adoption of soil and water control technology (SWCT) in Keita valley, a Semi-arid area of Niger, Sustainability 10: 288.

22. Arellanes P, Lee, DR (2003) The determinants of adoption of sustainable agriculture technologies: Evidence from the hillsides of Honduras, In Proceedings of the 25th International Conference of Agricultural Economists (IAAE), Durban, South Africa: pp. 693-699

23. Arene CJ, (1994) Discriminant analysis of small header farmer adoption potential and the prediction of extension cost in Nigeria: a comparative enterprise perspective. Journal of Extension System, vol. 10(1): pp. 4658.

24. Bello MES, Salau, Ezra L (2012) Analysis of factors influencing in continuance of technology adoption: the situation with some Nigerian farmers, Sustainable Agricultural Resources 1: pp 292-300.
25. Tiwari KR, Sitaula BK, Nyborg IL, , Paudel GS(2008) Determinants of Farmers' Adoption of Improved Soil Conservation Technology in a Middle Mountain Watershed of Central Nepal, Environmental Management 42: pp. 210-222.

26. Katungi E, Horna D, Gebeyeh, S, Sperling L (2011) Market Access, Intensification and Productivity of Common Bean in Ethopia: A microeconomic analysis, African Journal of Agricultural Research 6(2): 476-487.

27. Hazarika H, Alwang J (2003) Access to Credit, Plot Size and Cost Inefficiency among Smallholder Tobacco Cultivators in Malawi. Agricultural Economics 29(1): 99-109.

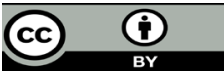

This work is licensed under Creative Commons Attribution 4.0 License

To Submit Your Article Click Here: Submit Article

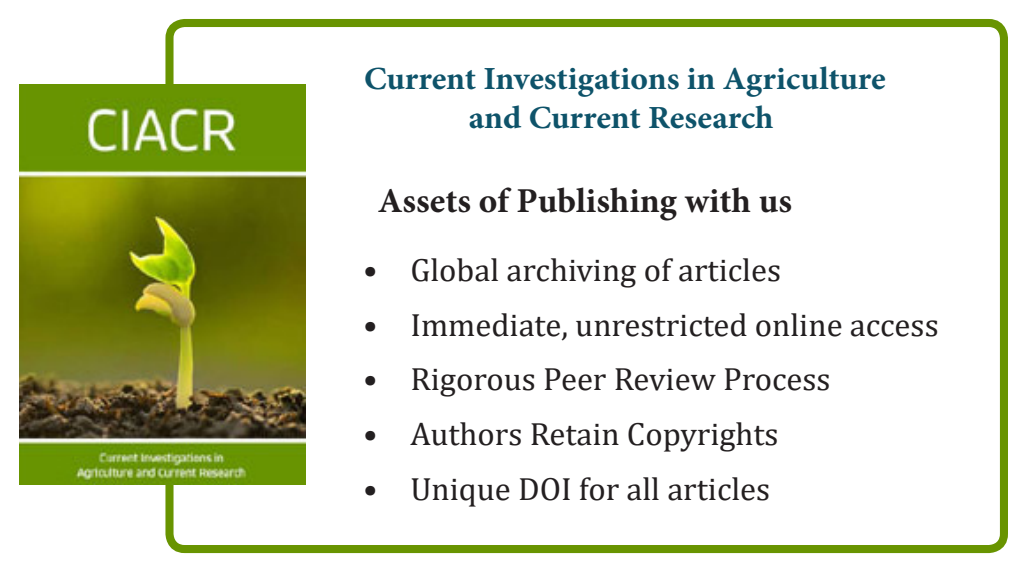

